\title{
Influencing Children: Limitations of the Computer-Human-Interactive Persuasive Systems in Developing Societies
}

\author{
Odji Ebenezer \\ Federal University of Technology, Akure/Industrial Design Department, Akure, 340252, Ondo State, Nigeria \\ Email: ezerodjimin@gmail.com
}

Received: 02 March 2020; Accepted: 08 May 2020; Published: 08 October 2020

\begin{abstract}
The phenomenon of product/business failure, as well as lack of environmental sustainability and learning limitations, is fast becoming a recurrent 'disease' for investors, designers, design sponsors and education policy makers in many developing countries with poor persuasiveness contributing a large quota to such failures. This has greatly hampered the education, poverty alleviation and developmental efforts of the governments of such societies. In a bid to curb this negative trend, children, who are major influencers in product purchase behaviours of adults, have been targeted specifically by persuasive designers, in an effort to both educate and adopt them as means of reaching the larger populace. However, most researches in current persuasive system designs are limited to the information communication/management technology or computerized environments. These systems are technology/internet-driven and many potential users, in reality, in the developing world, unlike the rest of the world is often made to believe, do not have open access to such systems. Unfortunately, the effectiveness of any persuasive system is dependent on its accessibility to its user(s). Technological backwardness (often concealed behind ostentatious self-deceptive facades) has led to the poor persuasiveness of local persuasive systems and products in the third worlds. Therefore, adopting a mixed method for establishing the factor(s) limiting the efficiency of the computer/electronic-human interaction persuasive systems (CHIPS) in South-West Nigeria (N=900), this study established the need to adopt more of the product/entityhuman interaction persuasive system (PEHIPS) as an effective alternative for third world countries as, based on the study outcomes, the CHIPS proved less relatively effective in comparison to PEHIPS in rural regions. It however recommends the alternating adoption of a combination of both computerized and entity/product driven systems for the purpose of optimizing persuasive effectiveness in developing worlds.
\end{abstract}

Index Terms: Accessibility-Persuasion Theory (APT), Computer-Human-Interactive-Persuasive-Systems (CHIPS), Product/Entity-Human Interaction Persuasive System (PEHIPS), Persuasive Design (PD), Persuasive Reach (PR), Poverty Alleviation, Developing Countries, Least Developed Countries (LDC).

\section{Introduction}

According to the Committee for development policy (CDP) of the United Nations, the characteristics of least developed countries (LDCs) include: poverty or income criterion, human assets index (HAI weakness) and economic vulnerability index (EVI) [1]. Developing countries like Nigeria are not exempted from these plagues as poverty, dwindling HAI and economic vulnerability are still prevalent as at the time of this study irrespective of what the rest of the world is led to believe. Some of these developing countries may flaunt a gross domestic product (GDP) above the poverty line (Gross National Income $>\$ 1,025$ ), a large percentage of their populace still live below the poverty line. The population explosion in some of these societies is impeding developmental efforts. Over 95\% of the world's population growth has been said to take place in developing countries and LDCs, Nigeria being an excellent example with a population estimation of between 140 to $>204$ million and its dependent groups outnumbering its income-generating labour force $[2,3]$. Their populations are estimated to grow even further in the next few years. For developing societies to benefit from this demographic augmentation, developing the entrepreneurial potential of its population is an integral prospect for economic development [4]. Studies have however linked entrepreneurial successes and failures to design and persuasion prospects and fiascos of products and contents from the manufacturing industries [5, 6]. Persuasion, targeted at children as a means of reaching the greater populace, is fast gaining greater grounds in the alleviation of entrepreneurial/product failures [7]. If well applied, persuasion may prove indispensable in the alleviation of the aforementioned problems of product/services and entrepreneurial failures. 
Persuasion may be adopted in various facets of life and development including politics, religion, education, environmental protection/sustainability and, more importantly for, economic or business purposes. Although may be approached from various perspectives including design, science and technology, prototyping, social interaction and more multidisciplinary collaborations, persuasion is generally a deliberate attempt to alter or enforce the behaviour of humans or other animals either as individuals or as a group. It comprises any or all messages conveyed by a design or design content or an agent on the same subject and have specific targets [8]. It is a premeditated presentation of influential messages in an attempt to encourage, reinforce or discourage specific behaviours. Objects, designs or technologies intended for this purpose are therewith identified as persuasive designs (PDs) or technologies. This concept of persuasion is not new in design. It has been a major objective of the field of design. While persuasion may be human to human, designers may delegate that act of persuasion to non-human entities, consciously seeking to change behaviours and attitudes [9, 10]. Computers and computer generated imageries are some of such objects or contents. It is no longer unusual to use computers and other electronic devices in attempts to change human behaviours [11]. An example is Captology, which involves using computers as persuasive technologies [12,13]. This is the idea in which persuasive designs are rooted.

Persuasive designs, created purposely to influence the consumer's, audience's, user's attitude or behaviour, have been described as designs with intent [14]. They bear ideas about their use, consumption and context and, hence, influence the way we think [15]. Sometimes, persuasive designs are visual entities intended to influence human behaviour positively or otherwise and they may be intended to work alone to achieve the persuasive intents of the designer. However, they may be intended to work together as a collection of entities to achieve the same purpose, therewith known as a persuasive system [16]. This collection of design entities may be in the context of a software, a web-site or a game system with which a user must interact to be influenced. In contrast, a persuasive system may be made up of entirely independent entities which are intended to work together to relate a persuasive argument.

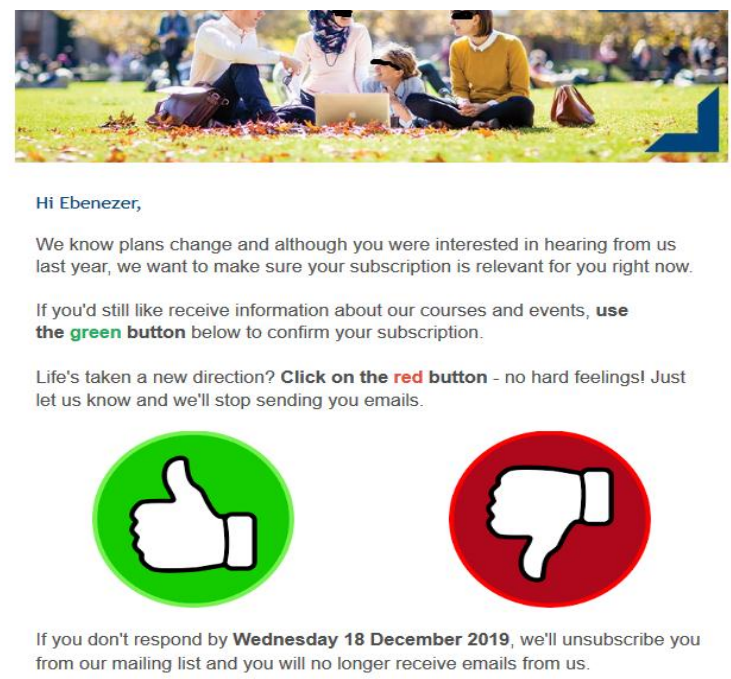

Fig. 1. An internet-based persuasive design intended to motivate the user to make quick decision, take immediate action and remain within the design sponsor's reach.

Noticeably, persuasive designs and systems are often adopted in fields such as e-commerce, marketing or advertising, sales promotion, social influence, politics, sustainability, public health, public relations and organizational management etc. Fig. 1, for example, was designed by a University's public relations' team to fish for potential students and retain existing applicants/students.

However, designers also tend to use it in any field requiring a target group's short-term or long-term engagement by encouraging continued routines, habits and or addictions [17], from which a design sponsor or a designer may benefit.

Children have come to constitute one of the major groups targeted by persuasive designers, especially designers or sponsors with intentions to sell products, brands, services or ideas. This situation is premised on the assertion that children constitute a very important group of consumers that influence the purchase of products [18].

This has given rise to various persuasive product designs, many of which are locked within persuasive systems intended to influence potential users or consumers to behave in targeted ways. However, based on several factors ranging from the level of technological exposure or development of the manufacturer as well as the targeted audience/consumer or user, the cultural environment within which the system is to function, the economic capacity of potential product users, product affordability to other factors such as system accessibility and so on, persuasive systems may not achieve the ultimate purpose of persuasion therewith referred to as less efficient or completely ineffective. An effective persuasive system should carry the potential user within its sphere through the following stages of persuasion: 
(i) The attention-arresting stage

(ii) The interest-sustenance stage

(iii) The action stage (where the user performs the targeted behaviour)

The above listed stages are all nonetheless dependent on the effective reach of the system. The effective reach of a persuasive system, as used in this study, is its efficacy in reaching its specific system targets (audience e.g. middle-aged children) with the system/design-embedded persuasive message(s) and the accomplishment of the specific system goals (i.e. behaviour change). Hence, an audience that cannot directly be reached (i.e. without direct access to the system), cannot be directly influenced. Such audience without direct access may only be influenced via other means such as peer influence or pressure. Therefore, the effective reach of any persuasive system is contingent upon two major elements namely: (1) its audience reach and (2) its goal achievement (attitudinal/behaviour change or influence or user-action). The internet/mail-based persuasive design shown in figure 1 was very effective, for example, in terms of the above listed stages. Therefore, this paper examined why some persuasive systems may not function optimally in developing countries like Nigeria, with emphasis on accessibility/effective reach, even though internet/computer-based persuasive designs are established effective means of influencing human behaviour.

\section{A. Persuasive System Types}

A key component in behaviour and attitude change is persuasion or persuasive designs [16]. Researches into users' attitudes, behaviour and persuasive designs have a long history [16]. Such enquiries began more than two decades ago when Fogg B.J., a persuasive designer and technologist, first introduced the term 'Persuasive design' in 1999 [19] although allusions could be made to earlier studies [20, 21, 22, 12]. Fogg's pioneering study has been followed by several studies into the art of persuasion through designs ranging from human-computer interaction to social interactions [16]. A third concept of interaction was earlier insinuated in another study [15] which is the entity or product-user interaction. These collectively suggest that there are three common interactive spheres within which human behaviour or attitude can be influenced namely (examples of designs in such systems are given in brackets):

a) The computer-human-persuasive interaction (e.g. computer or online games, softwares, interactive websites)

b) The social persuasive interaction (peer influence chains, political and religious campaigns) and

c) The product/entity-human persuasive interaction (e.g. persuasive product designs, advertisement, multimedia campaigns)

A previous study [23] described persuasion as a human interaction designed to influence the autonomous judgments and actions of other human beings. That is the social context. However, in the technological context, this responsibility of persuasion may be delegated to non-human entities such as computers or products, therewith known as persuasive technology. Fogg [12] described persuasive technology and designs as interactive technology or designs created for changing users' attitudes or behaviour. These interactive systems are used to communicate with the user or potential consumer and therefore can be used to influence his or her behaviour in the short or long run [16]. The focus of any persuasive system must be a technology-driven alteration, reinforcement or discouragement, of either behaviour or attitudes $[24,25]$. This is the premise on which the current study is built as accessibility to this technology is a major influencing factor in the success or failure of any persuasive system. A persuasive system to which accessibility is limited, or is non-existent in some cases, will ultimately be ineffective in achieving its design purpose, thereby leading to persuasion failure.

\section{B. Children as Targets of Persuasive Designs/Systems}

Persuasive drives are always aimed at reaching specific populations. This is what informs the designs and design contents especially at the local level. However, they may not necessarily be limitedly targeted at any specific population or age group in isolation. A prominent strategy has been established in a study in which a specific population, which influences the behaviour of other populations in particular ways, is deliberately targeted in a bid to reach out to another population [7]. For instance, if population A has verifiable influence on a targeted population B's behaviour, persuasive designers and sponsors may deliberately target population A as a means of reaching population B. For instance, medical doctors are targeted in order to reach some classes of patients; leaders are targeted in order to reach the followers; individuals are targeted in order to influence their peers. On this premise therefore, children are targeted so as to effectively influence the preferences or buying behaviour of their parents or guardians, for example. This notion has been stressed in a collection of previous studies [26, 7].

Obviously, the majority, if not all early aged and middle aged children do not directly buy or pay for the products for which persuasive designers target them. For example, many car adverts target children, but children are not the ones who eventually buy them. They merely influence their parents' preferences and eventual buying behaviours [7]. However, children are also targeted with persuasive designs and contents bearing persuasive arguments in favour of products directly used by children such as toys, clothes, games, bags and so on. This unique influential position held by 
children (fig. 2) makes them prominent targets for persuasive designers either within or outside the computerised environment, irrespective of the interactivity of the adopted system.

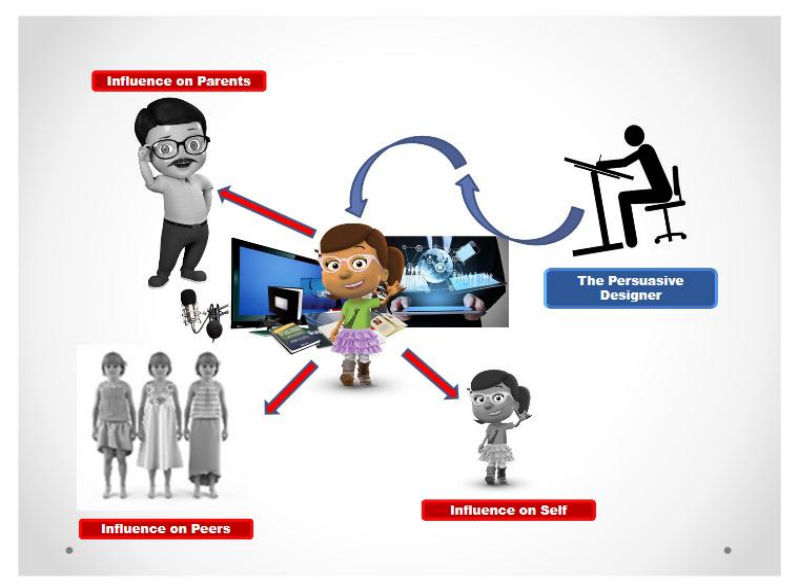

Fig. 2. Influence chain of children on self and others' preferences.

As shown in fig. 2, children influence their parents, their peers as well as themselves as individuals. Therefore, to reach the parents/guardians as well as their peers, who in turn expands the sphere of influence, the persuasive designer merely needs to influence the child in which case the child therewith becomes a key driver in the persuasive system [7]. A key driver serves as the major subject of focus in the adopted persuasive designs/components which constitute the system. It is intended to be, or used as, a means for reaching the greater populace. This means that the chief target of a persuasive system is often wider than its central subject of focus. Therefore, a persuasive system's dominant target or user, e.g. children, is first aimed at by the designer after which the social persuasive construct is allowed to take its course as shown in fig. 2.

However, one may wonder, why not reach adults directly for adult related products, services and with adult related contents and reach children with only children related persuasive messages so as to avoid possible "abuses by design" as inferred by Odji [7]? According to a previous study [8], many adults have devised ways to "cope" with, evade, manage or respond to persuasive attempts as the case may be or appear. This previous study, in its Persuasive Knowledge Model (PKM), in a bid to explain what targets of persuasive designs do in response to persuasion efforts, described the essential role of the persuasive knowledge gained over the years. Adult consumers possess greater tendencies to misconstrue a persuasion attempt than do children [27]. This notion has been averred in studies such as Rule et al [27], Friestad et al [8] and Odji [7]. Generally, consumer's capacity to judge persuasion drives as appropriate, unbiased or manipulative, coercive and such like depends on their tactic conceptions and beliefs which are more pronounced in adult targets than in children [8]. This situation, one may assume relatively may limit, to some extent, direct persuasive reach to adult targets as compared to children which might have informed the enormous attention directed towards reaching children by persuasive designers [7]. Therefore, rather than attempting to directly persuade these adult targets, 'why not reach them through the children who are seemingly easier to persuade (or so it seems)?' Hence, children are directly targeted by persuasive designers and design sponsors as a means of reaching the greater populace. For examples, persuasive adverts that feature children as lead characters are increasingly becoming more popularly adopted. However, children are merely secondary targets adopted as key drivers for the propagation of persuasive messages [7]. Adults, who eventually pay for the products, cast the votes, have the final say in the family decision making and so on, are the primary targets. Hence, children are targeted by persuasive designers as a means of reaching adults as well as other children.

\section{SOME Possible Limitations of The Human-Computer Interactive Systems in Non-Computerised Environments}

Adopting children as key drivers in reaching the greater populace with persuasive messages/arguments has enjoyed some level of success especially in the more technologically advanced societies, if not much success already, even though such success may consequently constitute health, eating or behavioural complications to children's health in the long run [7]. However, the success of a system depends largely on factors such as its accessibility, its relative unobtrusiveness, interactivity, nature of the environment as well as on the system credibility as perceived by the user or audience. Perhaps, three of the most important dependent factors are the level of accessibility enjoyed by the target population or key drivers to the system, the type of system adopted as well as the environment from whence the system is run or in which it operates.

Systems can be classified depending on the above enumerated factors. However, for the purpose of this study, persuasive systems are classified into two major categories namely: 
a) Computer/internet mediated interactive persuasive systems

b) Non-computer/internet mediated or non-interactive persuasive systems

Computer/internet mediated interactive persuasive systems involve a one-time or many times, often step by step, interaction of the user with the system intended to influence the autonomous judgments and actions of the target audience/user. Examples include self-tracking devices and mobile applications which aid in maintaining health and provide goals support in changing our behaviours [23, 28]. They have been described as "computerised software or information systems," thus creating the impression that persuasive designs/systems are basically computerised [24]. The current study opposes this insinuation on the premise that persuasion can be achieved both within the computerized or electronic environment and the non-computerised environment. Persuasive adverts, for example, are persuasive components. However, such adverts may not necessarily be embedded in a computerised persuasive system. If persuasion was only possible via the computerised environment, then many or some people from the developing world may not be persuaded. Therefore, a non-computerised system might then be well complementary in persuasive campaigns in third worlds, a notion investigated in this study.

All persuasive systems or designs present the user/audience with one form of argument or another. While the noninteractive persuasive systems merely present the user with an argument, affording him/her the freedom to decide, the more interactive persuasive systems often present their arguments in a step by step construct therewith tailoring the user's decision chain. While many non-interactive persuasive systems are not necessarily computerised, more interactive persuasive systems are well computerised. No wonder then they were termed as "computerised software or information systems" [24]

A conceptual and theory-creating study by Oinas-Kukkonen et al. [25], suggesting a framework for persuasive systems design, listed some of the entities that constitute the human-computer persuasive interaction as including web, the internet, software, mobile, and other ambient technologies. All such are referred to as persuasive technologies. A growing number of such persuasive designs, systems and services are being developed to change users' attitudes or behaviour or both [25]. While the Fogg Behavioural Model (FBM) [19] is the key construct upon which most of such persuasive researches are based, yet, new frameworks and models have been introduced, such as the Unified Theory of Use and Acceptance of Technology model [29, 30], the Technology Acceptance Model [16], Theory of Reasoned Action and the Theory of Planned Behaviour [16].

Although, some studies have also been conducted in the realm of entity-human persuasive system [27] e.g. Friestad et al [8], unfortunately, most of the specified frameworks and models are premised within the sphere of humancomputer interactions only, meaning that except a user interacts with the computer system itself, a mobile or electronic device, a web-site, software or the internet, there may be little or no chance of being influenced by the system, limiting their possible reach to only children or users who have access to devices and entities within the system. A good example is the interactive persuasive Mathematics game designed for primary school children intended to assist them in developing interest in mathematics [31]. They are computer mediated persuasions. However, such persuasive drives can only reach children who have access to host persuasive technologies. Within the human-computer interactive system, a designer can only reach a target audience or users with access to the system. While human-computer persuasive system may prove relatively effective in a very civilized and technologically advanced and exposed community, the same may not be said of a less technologically advanced or less exposed community where some children may not have access to the entities within the system. Perhaps, an entity-user persuasive interaction will suffice. Entity as adopted in this study may be a persuasive product, object or contents intended to persuade, hence may also be referred to as a product-user persuasive system. Therefore, to avoid undue assumptions, on which notions pertaining to the technological advancement and access to technologies in third world economies like Nigeria, Togo, Ghana and such like are based, this study investigated the level of accessibility to technology children enjoy using Western Nigeria as a case study. This position is premised on a proposed Accessibility-Persuasion Theory (APT):

The greater the accessibility enjoyed by a user to persuasive technologies, the higher the chances of persuasion and vice versa.

This theory is positioned on the popular notion that persuasion is a 'computerised' endeavour. The theory was tested in this study's hypotheses.

\section{Pros of The Product/Entity-Human Interaction Persuasive System (PEHIPS)}

A persuasive system include all adopted entities intended to work together to achieve the purpose of persuasion. While the elements of a human-computer persuasive interaction is locked within the sphere of a software, a website or an electronic/mobile device and are dependent, the entities in a product-user persuasive interaction system are independent entities intended to work together to achieve a particular persuasive goal. Different persuasive system development methodologies exist [13]. One of such methodologies had been earlier projected. Fogg (2003) proposed a functional triad: Ability, Motivation and Trigger for the design of such a persuasive system. These three enumerated factors must work together for a target behaviour to take place. Fogg's functional triad, and the design principles 
presented in it, makes up the foremost utilized conceptualization of persuasive system designs [25]. A flaw of such models as Fogg's model is that they are locked within the sphere of human-computer interaction which obviously omits potential users or consumers without access to the computer or other human-computer interaction system entities within which the influence chain is set up. Although, computers have become rather popular over the years, however, it would be overly ambitious to assume that the target population of this study, children in developing worlds, has access to computers. Therefore, this study accessed the level of accessibility the target population enjoys to computers and other human-computer persuasive system hosts such as the internet.

Various sponsors and professionals adopt persuasion for different purposes ranging from health improvement to environmental protection and, more popularly, product sales and promotions. If all members of the target population have access to the computerized environment or devices, then persuasion may be more effective. However, in the absence of adequate access to required technologies, the entity/product-user interaction persuasive method provides an alternative even though most research emphasis has been laid on the human-computer interaction system [9]. Unfortunately, most of the human-computer interaction systems can only be used to attract attention to products which may often not be a part of the persuasive system, while the product-user interaction system may have the product under consideration as a prominent or contributing part of the system.

Another advantage that the entity-human persuasive system may possess is its relative unobtrusiveness leaving the user with more flexible choices in decision making. The construct of unobtrusiveness in persuasive designs evaluates the association between the system, the user, and the context, hence measuring how well a system fits into the environment in which it is adopted [28]. It is one of the key constructs in persuasive system design [28]. The most effective persuasive designs are subtle and less obtrusive in impact. In persuasion, the line between distraction and influence is very thin and a design can easily fall into any of these aforementioned categories thereby constituting a distraction or a behavioural influence/trigger with the former being an easy turnoff for many system users, reducing user-perceived system credibility. Therefore, it could be surmised that persuasive designs should always be as unobtrusive as possible. For example, persuasive designs/systems should not interfere with whatever task a user essentially desires to achieve at any particular time, yet they should still clearly achieve their intended persuasive purposes. Of course, relative intrusiveness is inherent in all persuasive designs. Yet, designers should strive to sustain moderate level of unobtrusiveness in persuasive system designs. In this context, the entity/product-human persuasive system has relative advantage over the human-computer persuasive system which in some or many cases can be relatively more obtrusive and intrusive. A persuasive campaign is more likely to succeed when the targeted user or audience is not necessarily fully aware that his/her thoughts, decisions, attitude or actions are being deliberately, directly or indirectly, tailored or manipulated.

\section{E. Sub-Sets of The Product/Entity-Human Interaction Persuasive System}

While the human-computer interactive persuasive system is locked within the internet/computer environment, the entity-human interaction persuasive system may also be within the electronic sphere but are usually independent of the internet. For example, a calorie level detector is an electronic device, but may not necessarily need the internet. Many entity-user interactive systems may even be completely non-electronic and non-internet based.

An entity-user interactive system may on this premise be made up of two or more of the following:

a) Persuasive product designs (may or may not be electronic)

b) Persuasive product packages

c) Persuasive multimedia (including:

(i) persuasive television promotional clips

(ii) persuasive audio advertisements

(iii) persuasive texts

(iv) persuasive multisensory instructional visuals (all of which may or may not be electronic or internet based.)

d) Persuasive Billboards

e) Persuasive Fliers

f) Persuasive banners and posters and so on [7].

This type of persuasive system may not necessarily require very complex computer or electronic devices to engage the user. Sometimes, a mere television set, a display/design space or the product itself may be all that is required to convey a persuasive message to the potential user or audience. However, the query remains which one is more effective in persuasion in the third world context: the CHIPS or the PEHIPS? Perhaps, both? This study was expected to reveal which one was more effective in less urbanised or less computerized societies. 


\section{Method}

Western Nigerian states are considered home to some commercial hubs amongst developing countries [5]. It is also considered to be relatively technologically exposed. Therefore, the empirical study was conducted in western part of Nigeria adopting a survey method. The population for the study included middle-aged (7-10 years old) children in public and private primary schools as schools are considered easier means, by the researcher, to reach children within similar age range in large numbers. The lottery method was adopted for selecting the schools from which samples were chosen. 900 children were sampled in a total of 36 focus groups. Each of the 24 groups in the urban areas had 25 pupils 300 children were sampled in a parallel enquiry conducted in rural regions comprising 12 groups of 25 members each. Therefore, on grand total, $\mathrm{N}=900$. The children were randomly sampled. Analysis were carried out using descriptive statistics including frequencies and percentages and presented in charts and tables. Chi-Square statistics (equ.1) was used in analysing the study hypotheses. Mathematically, Chi-Square is represented thus:

$$
X^{2}=\sum\left\lfloor\frac{\left(f_{e}+f_{o}\right)^{2}}{f_{e}}\right\rfloor
$$

Where $\mathrm{X}^{2}=$ Chi-Square, $f_{e}=$ Expected values and $f_{o}=$ Observed values. The decision rule was to reject the null hypothesis if obtained significance level ( $p$-value) is less than alpha (the predetermined significance level, $\alpha=0.05$ ) [32].Environmental cleanliness/sustainable environmental behaviour and good eating/table manners were adopted as target behaviours in the persuasive drives of this study. The permission/consents of concerned parents/guardians and respective Local Government Education Authorities were obtained where necessary. Participation was strictly on voluntary basis and was at no cost whatsoever to the participants.

\section{A. Research Questions}

The following research questions guided the course of this study:

1) Do children in developing societies truly have adequate access to persuasive technologies (the internet, computers, mobile devices, etc.)?

2) Does accessibility in rural areas defer from accessibility enjoyed by children in urban areas?

3) Is there significant association between level of accessibility to persuasive technologies and the level of persuasion in developing worlds?

4) Which is currently more effective in reaching the developing world: product/entity-human persuasive system or the internet mediated computer-human interactive persuasive system?

The study was divided into two phases. Phase 1 was to answer research questions 1 and 2 while phase 2 was to answer research questions 3 and 4 . The investigations were expected to reveal the accessibility level of children to CHIPS in rural areas relative to PEHIPS in comparison to their urban counterparts and their corresponding level of persuasion. Since the effectiveness of any persuasive system is dependent on its accessibility to its users, therefore a relatively low accessibility level of the subjects to CHIPS was expected to indicate its ineffectiveness or limitation in the study area and vice versa. A relatively lower level of persuasion also indicated ineffectiveness of a persuasive system.

\section{B. Research Hypotheses}

$\mathrm{H}_{01}$ : There is no significant association between level of accessibility to persuasive technologies and the level of persuasion in developing worlds.

$\mathrm{H}_{02}$ : There is no significant difference in the effective reach of computer-human interactive persuasive system and the entity/product-human persuasive system in developing worlds.

\section{Results and Analyses}

Table 1. Gender distribution of study participants

\begin{tabular}{lllll}
\hline S/N & $\begin{array}{l}\text { Gender } \\
\text { (children) }\end{array}$ & $\begin{array}{l}\text { Rural } \\
\text { Areas }\end{array}$ & $\begin{array}{l}\text { Urban } \\
\text { Areas }\end{array}$ & Row Total \\
\hline 1. & Males & 147 & 295 & 442 \\
2. & Females & 153 & 305 & 458 \\
Column Total & 300 & 600 & Grand Total = 900 \\
\hline
\end{tabular}


As indicated in Table 1, a grand total of 900 children were involved in the study including 442 boys (49.11\%) and 458 girls (50.89\%). This eradicated all possible gender bias from the study. This gender fairness, rather than a deliberate effort in the current study, was more of an accidental confirmation of the outcome of previous studies which indicates an increasingly reduced gap between the formal educational attainment between girls and boys in developing countries like Nigeria [33]. No economic distribution was carried out as children were assessed irrespective of their economic background. The study proceeded in two major phases as follow:

\section{A. Assessing The Participants' Level of Access To Chips}

All children in the population were involved in the first phase of this study, both rural and urban based. All participants were sent messages [persuasive texts (rendered as simple as possible for primary pupils to comprehend) and still images only], except those without emails or social media handles. Theirs (if they had any) or parents' emails or social media handles/contacts were collected for purposes not disclosed to them and the persuasive messages were sent to them. Responses to messages were recorded as it was included in the messages that recipients were to acknowledge the receipt.

This phase involved the elicitation of self-reports from the participating children. Participants were asked how many times on the average they had access to computers, internet-enabled mobile and other ICT devices or platforms etc. The enquiry was performed over a period of one month (30 days). Children that had access to persuasive technologies for at least 21 days and above were considered as having high access. Children that had at least 11 to 20 days access were considered to have moderate access while children were rated as having low or no access if they had only a maximum of 10 days and below or no access at all to ICT mobile or table devices. The responses from the urban enquiry, involving areas such as Yaba, Akure, Somolu, Ojo, Ibadan etc., were as recorded in fig. 3.

As recorded in fig. 3, approximately $33 \%$ of the children in urban areas assessed had high access to persuasive technologies. Approximately $40 \%$ only had moderate access to persuasive technologies while $27 \%$ of the urban children assessed had low or no access to persuasive technologies. This shows that the majority of urban children in developing areas sampled only had moderate access to persuasive technologies.

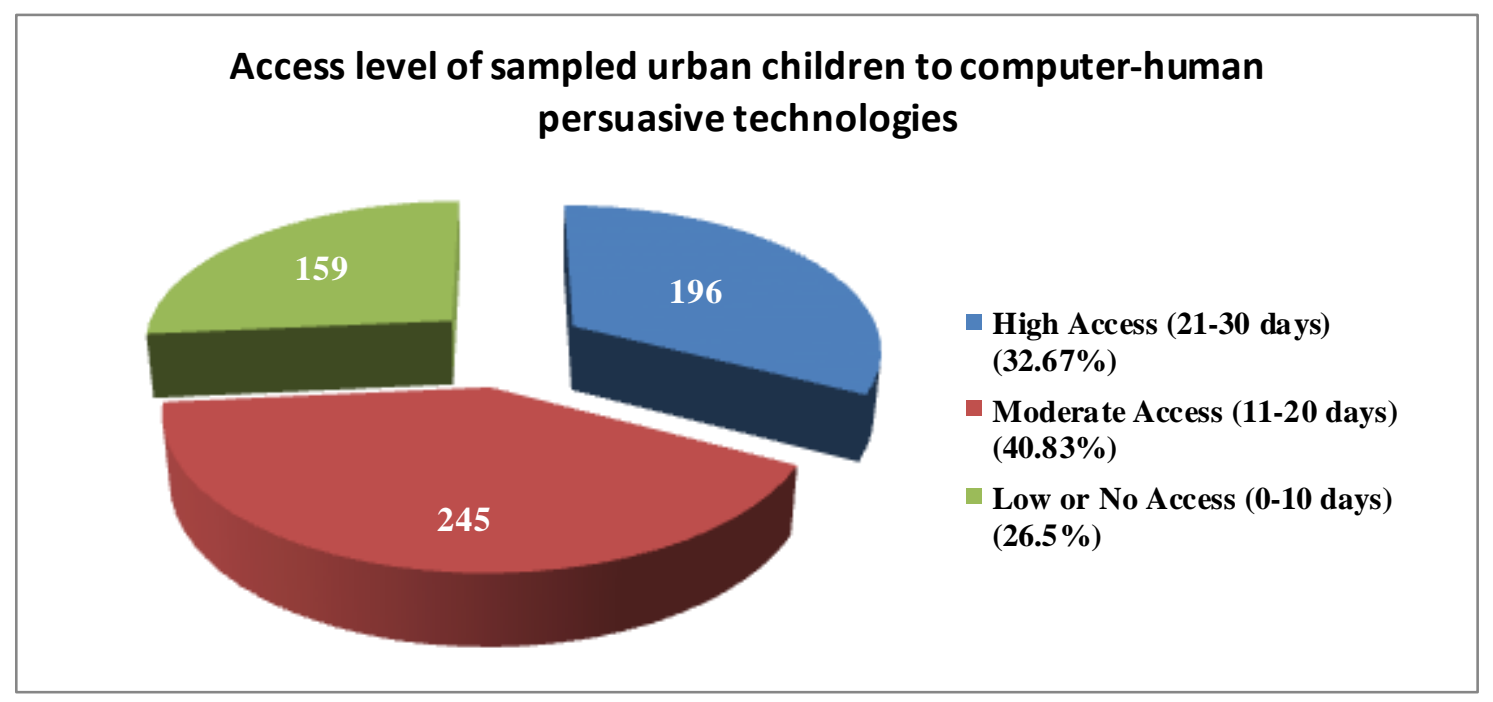

Fig. 3. Access level of the children sampled in the urban regions to CHIPS.

This may have a few implications, but, perhaps, one of the most important ones will be inconsistency in the persuasion process, which hinders the persuasive effectiveness, as constant exposure is germane for the success of persuasive campaigns [35, 36, 37, 38].

A parallel enquiry, of half the initial urban population,

$\mathrm{N}=300$, was conducted in the rural parts of the study area like Muwo, Oba-ile, Atinporomeh, etc. in South western Nigeria which were much less urbanised. The results are as presented in the fig. 4. Some children in the rural areas had no emails to present as neither they nor their parents/guardians had access to persuasive technologies.

As shown in figure 4 , the majority of the sampled children in the more rural areas had little or no access to persuasive technologies at $62 \%$ as opposed to the $26.5 \%$ accessibility reported in the more urban areas. 


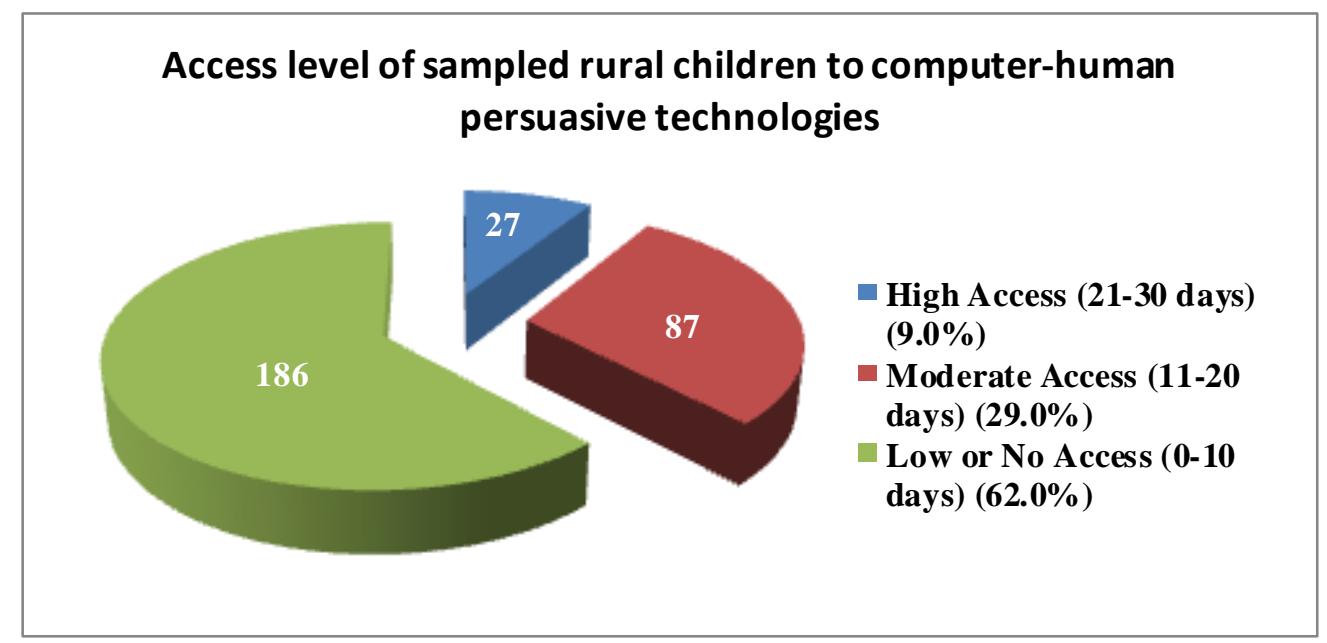

Fig. 4. Access level of the children sampled in rural areas to CHIPS.

Only $9.0 \%$ of the sampled rural children had high access to any form of persuasive technologies in clear contrast to the percentage reported in the more urban areas (at 32.67\%). With $29.0 \%$ of the rural area resident children recorded to be having moderate access to persuasive technologies, the results indicates a relatively glaringly high inaccessibility to persuasive technologies amongst sampled children in the rural areas.

\section{B. Comparative Assessment Level of Access to Chips}

To answer research question 2, a comparative assessment of the accessibility of children in rural areas was compared to the accessibility enjoyed by children in urban areas. For the purpose of comparing the access level of the rural and urban area children, the urban area data was divided by two to even up the sample sizes and reduce possible bias. Therefore, for the urban area, $\mathrm{N}=600$ and for the rural, $\mathrm{N}=300$. The results are as summarized in fig. 5.

As shown in fig. 5, only $9 \%$ of children in more rural areas had high access to persuasive technologies as compared to $32.7 \%$ in the more urban regions. $11.83 \%$ more children in the urban areas $(40.83 \%)$ had moderate access to persuasive technologies as opposed to $29 \%$ in the rural areas. Only $26.5 \%$ had low or no access to persuasive technologies in the more urban regions as compared to the rural areas with $62 \%$. Summarily, the results indicates an inverse relationship between urbanization and level of accessibility/inaccessibility as the more rural areas had relatively high inaccessibility to persuasive technologies while the more urban areas recorded relatively lower inaccessibility to persuasive technologies. Therefore, the possibilities of effective persuasive reach in urban areas was greater than that of the less urban or rural areas. This indicates that only mostly children in urban areas would be commendably reached with computer/internet mediated persuasive strategies (as at the time of this study). But how effective are computer/internet mediated persuasive strategies? Does the relatively high access level of children in the urban areas yield corresponding persuasion? Is there any significant relationship between the level of access to persuasive technologies and persuasion level of children? These were tested in the hypotheses of the study.

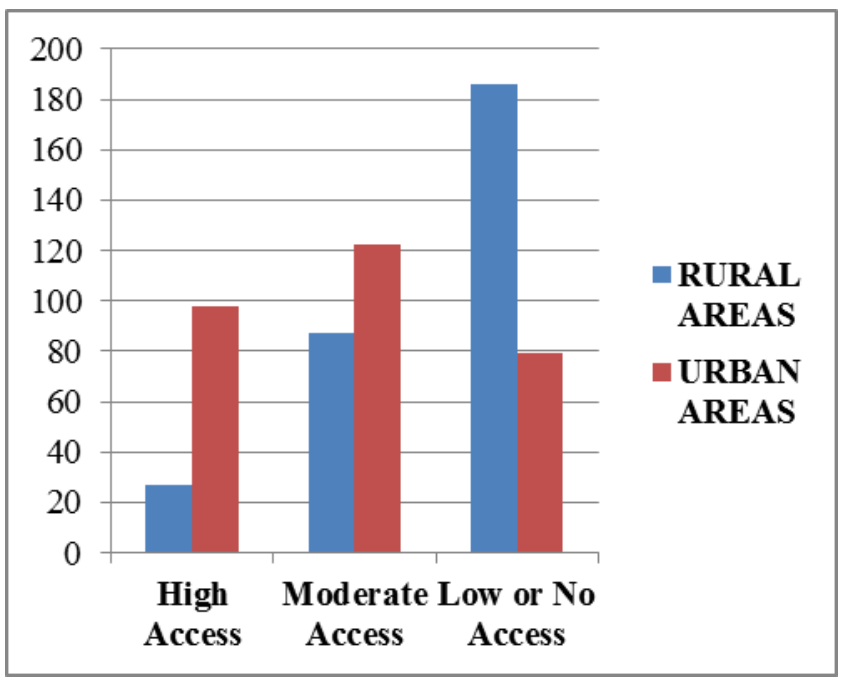

Fig. 5. Summary of the comparative analysis of the access level of the children sampled in rural and urban areas. 
For the second phase of this study, only data collected from the children in the more urbanised areas were analysed and used for the purpose of answering research questions 3 and 4.

For the purpose of answering the research question 3, children were rated as fully persuaded if they responded to messages and also showed at least one behavioural adjustment of not littering the environment or eating habits. They were rated as moderately persuaded if they either only responded to messages or only showed at least one behavioural adjustment of not lithering the environment/eating habits. They were however rated as not persuaded if they neither responded to messages nor only showed behavioural adjustments of not lithering the environment/eating habits over the period of study. The results were as presented in Table 2 .

Table 2. Relationship between level of access to persuasive technology and the level of persuasion

\begin{tabular}{|c|c|c|c|c|}
\hline $\mathrm{S} / \mathrm{N}$ & $\begin{array}{l}\text { Persuasion vs } \\
\text { Access level }\end{array}$ & $\begin{array}{l}\text { Fully } \\
\text { Persuaded }\end{array}$ & $\begin{array}{l}\text { Moderately } \\
\text { Access } \\
\text { Persuaded }\end{array}$ & $\begin{array}{l}\text { Not } \\
\text { Persuaded }\end{array}$ \\
\hline 1 & High Access & 58 & 72 & 66 \\
\hline 2 & $\begin{array}{l}\text { Moderate } \\
\text { Access }\end{array}$ & 83 & 75 & 87 \\
\hline 3 & $\begin{array}{l}\text { Low or No } \\
\text { Access }\end{array}$ & 21 & 36 & 102 \\
\hline $\begin{array}{l}\text { Total } \\
\text { Granc }\end{array}$ & Total $=600$ & 162 & 183 & 255 \\
\hline
\end{tabular}

From Table 2, from the total of 196 (32.67\%) who had high access to persuasive technologies in the study areas, only 58 were fully persuaded. 72 of them were moderately persuaded while 66 of them were not persuaded in anyway. 83 of the $245(40.83 \%)$ of the study participants who had moderate access to persuasive technologies were fully persuaded in the course of the study. 87 of them were not persuaded. A record high $102(64 \%)$ of the 159 (26.5\%) participants who had low or no access to persuasive technologies showed no evidence of been persuaded. The association between level of accessibility to persuasive technologies and the level of persuasion was tested in hypothesis 1.

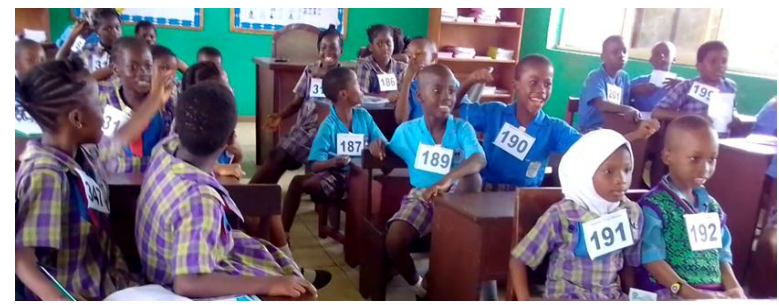

Fig. 6. Children in one of the focus groups.

To answer research question 4, a total of 300 out of the initial 600 children from the urban parts of the study area, placed in groups A and B, were adopted. Group A was made up of 150 of the most promising of the children who had high access to persuasive technologies and Group B was made up of 150 of those who had low or no access to persuasive technologies. Group A was exposed to computer mediated interactive persuasive system while members of group B were exposed to product/entity-human persuasive system made up of posters and instructional videos via television in focus group settings (fig. 6).

Children were rated as fully persuaded if they showed behavioural adjustments of both not littering the environment and good eating habits. They were rated as moderately persuaded if they either only showed at least one behavioural adjustment of not lithering the environment or good eating habits. They were however rated as not persuaded if they showed no behavioural adjustments pertaining to the environment or good eating habits over the period of study. The results are as presented in Table 3.

Table 3. The effect of persuasive system type adoption on level of persuasion recorded in the course of the study

\begin{tabular}{lllll}
\hline S/N & $\begin{array}{l}\text { Persuasive System } \\
\text { Type vs Persuasion } \\
\text { level }\end{array}$ & $\begin{array}{l}\text { Fully } \\
\text { Persuaded }\end{array}$ & $\begin{array}{l}\text { Moderately } \\
\text { Access } \\
\text { Persuaded }\end{array}$ & $\begin{array}{l}\text { Not } \\
\text { Persuaded }\end{array}$ \\
\hline $\mathbf{1}$ & Group A & 33 & 61 & 56 \\
$\mathbf{2}$ & Group B & 29 & 86 & 35 \\
Total & 62 & 147 & 91 \\
Grand Total $=300$ & & & \\
\hline
\end{tabular}

As shown in Table 3 above, only 33(22\%) of the 150 participants who were exposed to the computer/internet mediated persuasive system showed evidence of been fully persuaded. 61(40.67\%) of them were moderately persuaded while 56(37.33\%) showed no evidence of been persuaded. Only $29(19.33 \%)$ of those exposed to the product/entity 
mediated persuasive system showed evidence of full persuasion. This seemed higher than the figure recorded for the computer mediated persuasive system. However, the figure recorded, 86 (57.33\%), for those moderately persuaded amongst participants exposed to the product/entity mediated persuasive system was relatively higher. Only $35(23 \%)$ of those exposed to the product/entity mediated persuasive system showed no evidence of been persuaded as opposed to the $37.33 \%$ recorded for the computer/internet mediated persuasive system. These results were tested in hypothesis 2 to assess the appropriateness of each persuasive system type in developing areas.

\section{Hypotheses Testing}

The data recorded in Tables 2 and 3 were adopted for the testing of the study hypotheses using Chi-Square analysis. Hypothesis 01

$\mathrm{H}_{01}$ : There is no significant association between level of accessibility to persuasive technologies and the level of persuasion in developing worlds.

$\mathrm{H}_{\mathrm{a} 1}$ : There is a significant association between level of accessibility to persuasive technologies and the level of persuasion in developing worlds.

Table 4. Contingency table showing the association between access level of children to persuasive technologies and persuasion level

\begin{tabular}{|c|c|c|c|c|c|c|}
\hline \multicolumn{3}{|c|}{$\mathbf{S} / \mathbf{N}$} & \multirow{2}{*}{$\begin{array}{l}\text { Fully Persuaded } \\
58(52.92)[0.49]\end{array}$} & \multirow{2}{*}{$\begin{array}{l}\begin{array}{l}\text { Moderately Access } \\
\text { Persuaded }\end{array} \\
72(59.78)[2.50]\end{array}$} & \multirow{2}{*}{$\begin{array}{l}\text { Not Persuaded } \\
66(83.30)[3.59]\end{array}$} & \multirow{2}{*}{$\begin{array}{l}\text { Row Totals } \\
196\end{array}$} \\
\hline $\mathbf{1}$ & High Access & & & & & \\
\hline 2 & $\begin{array}{l}\text { Moderate } \\
\text { Access }\end{array}$ & & $83(66.15)$ [4.29] & 75 (74.72) [0.00] & $87(104.12)$ [2.82] & 245 \\
\hline 3 & $\begin{array}{l}\text { Low or } \\
\text { Access }\end{array}$ & No & $21(42.93)$ [11.20] & $36(48.50)$ [3.22] & $102(67.58)$ [17.54] & 159 \\
\hline \multicolumn{3}{|c|}{ Column Totals } & 162 & 183 & 255 & 600 (Grand Total) \\
\hline
\end{tabular}

The Chi-Square test of independence was performed to examine the relation between the accessibility to persuasive technologies and the level of persuasion children experienced in the study area as detailed in Table 4. The relation between these variables was significant, $X^{2}(4, N=600)=45.6473, p<.00001$. Children with higher access to persuasive technologies were more likely than children with lesser or no access to persuasive technologies to be persuaded or influenced. Since the p-value is less than 0.01 (the predetermined significance level), we reject the null hypothesis $\left(\mathrm{H}_{01}\right)$ and, thereby, accept the alternate hypothesis $\left(\mathrm{H}_{\mathrm{a} 1}\right)$ which establishes a significant relationship between access level to persuasive technologies and the level to which children are persuaded or influenced.

\section{Hypothesis 02}

$\mathrm{H}_{02}$ : There is no significant difference in the effective reach of computer-human interactive persuasive system and the entity/product-human persuasive system in developing worlds.

$\mathrm{H}_{\mathrm{a} 2}$ : There is a significant difference in the effective reach of computer-human interactive persuasive system and the entity/product-human persuasive system in developing worlds.

Table 5. Contingency table showing the association between the level of persuasion children experience when exposed to computer/internet mediated and product/entity mediated persuasive system

\begin{tabular}{|c|c|c|c|c|c|}
\hline $\mathbf{S} / \mathbf{N}$ & & Fully Persuaded & $\begin{array}{l}\text { Moderately Access } \\
\text { Persuaded }\end{array}$ & Not Persuaded & Row Totals \\
\hline 1 & $\begin{array}{l}\text { Access to computer mediated } \\
\text { interactive persuasive system }\end{array}$ & $33(31.00)[0.13]$ & $\begin{array}{llll}61 & (73.50) & {[2.13]}\end{array}$ & $56(45.50)[2.42]$ & 150 \\
\hline 2 & $\begin{array}{l}\text { Access to Product/entity-human } \\
\text { persuasive system }\end{array}$ & $29(31.00)[0.13]$ & $86(73.50)[2.13]$ & $35(45.50)[2.42$ & 150 \\
\hline \multicolumn{2}{|c|}{ Column Totals } & 62 & 147 & 91 & $\begin{array}{l}300 \text { (Grand } \\
\text { Total) }\end{array}$ \\
\hline
\end{tabular}

The Chi-Square test of independence, at alpha value $\mathrm{p}<0.01$ was performed to examine if there is a significant difference between the levels of persuasion children experienced in the study area in relation to the persuasive system type to which they had access as detailed in Table 5. The relation between these variables was significant, $\mathrm{X}^{2}(2, \mathrm{~N}=$ $300)=9.3559, \mathrm{p}=.009298$. In other words, there is a significant difference in the proportion of children who were persuaded through exposure to computer/internet mediated persuasive system and those exposed to entity/product mediated persuasive system. Since the $\mathrm{p}$-value $(\mathrm{p}=.009298)$ is less than 0.01 (the predetermined significance level), we fail to accept the null hypothesis $\left(\mathrm{H}_{02}\right)$ and, thereby, accept the alternate hypothesis $\left(\mathrm{H}_{\mathrm{a} 2}\right)$ which establishes a significant difference between the levels of persuasion children experienced in the study area in relation to the persuasive system type to which they had access. 


\section{Discussion}

As predicted earlier and established in the hypothesis 1 test of this study, the effective persuasive reach of any system of persuasive technologies is contingent upon the access the potential target/audience has to it (Table 4). An inaccessible system will have little or absolutely no persuasive reach in relation to the target. With the results presented in figures 3, 4 and 5, 345 of the sampled population had no access to computer/internet mediated persuasive technologies as opposed to 223 children who had commendable access to such technologies. This casts shadows on the effectiveness of CHIPS as a major persuasive medium for reaching targets (with children as key drivers) in developing or less developed communities.

In furtherance of this notion, according to previous researches, 1 out of every 5 middle-aged children that are not in school are found in Nigeria (over 10.5 million children), the majority of whom reside in the rural areas [34]. Reconciling this reality with the statistics shown in figure 5, indicating that the majority of children in school in the rural areas still do not have sufficient access to persuasive technologies, goes on to confirm the current inefficiency of the computer/internet mediated persuasive technologies in less developed regions, as only children that were in school were sampled. If the greater numbers of children being educated do not have sufficient access to persuasive technologies, which provides for adequate persuasion, how much less access will those of them who are not in school have?

Within the human-computer interactive system, a designer can only reach a target audience or users with access to the system. While human-computer persuasive system may prove relatively effective in a very civilized and technologically advanced and exposed community, the same may not be said of a less technologically advanced or less exposed community where many children, as revealed in this study and contrary to popular notions of greater technological exposure, may not have access to the persuasive technologies within the internet/computer system. Reasons for this phenomenon, although subject to further research, may be due to the following factors:

(i) Economic factor: Not everyone can afford the gadgets/devises needed to access the systems.

(ii) Cultural factor: Some parts of the African culture limit some African parents from allowing their children to be exposed to the internet at a very early stage. This, some believe, may lead to 'corruption from the West'.

(iii) Religious factor: Africa is a very religious sphere and some religions prohibit their 'faithfuls' from exposure to the internet and other related technologies for 'purity' or spiritual reasons. Perhaps, this as well as the cultural factors are partly premised on the notion that exposure to the internet/computers and other related technologies may expose a child to negative influences above their age grade [7]. There are also religious sects who believe education and technologies are 'sinful'. A good example is the Northern Nigeria based Boko haram insurgents who have greatly limited educational and other forms of development and accessibility in the affected areas. LDCs like Yemen and Afghanistan also suffer a similar setback as at the time of publication.

(iv) Educational factor: Some parents were of the belief that early exposure to the internet and other related technologies may likely limit a child's academic concentration and performance in school.

(v) Parental factor: Some parents' self or culturally perceived need to 'protect' their children from undue exposure to 'western pollution' via the internet has also limited the access of children to the computer/internet.

The result obtained for the hypothesis test 2 showed that children in the sampled area were more likely to be persuaded by an entity/product mediated persuasive system than by a computer/internet mediated persuasive system. This is not unconnected to the level of access the sampled children had, or did not have, to the said persuasive systems. While children in the more urban areas had more access to internet/computer mediated persuasive technologies, the majority of children in the rural areas had little or no access to persuasive technologies and inaccessibility impedes thorough efficient persuasive reach.

\section{Recommendations}

Based on the results presented in this study as well as in other reviewed studies, the following recommendations are proposed:

1) Adoption of design entities and persuasive technologies to which the majority has easy access rather than merely blindly copying the western world who are more technologically advanced. This will improve persuasive reach thereby encouraging entrepreneurial and learning successes.

2) Adoption of the selective combination of both the computer/internet mediated and the product/entity mediated persuasive systems in developing worlds in order to reach the larger populace irrespective of their access level to persuasive technologies since the effectiveness of any persuasive system is contingent upon its audience reach and its goal achievement (attitudinal/behaviour change or influence or user-action). 
3) Adoption of a functional 'dynamic link' to connect all adopted design entities in any persuasive design system. This is subject to further research. Dynamic-links are symbols, entities or characters, etc. common to, or found in, all design entities in a persuasive system [7].

4) Further case-specific studies should be conducted to decipher the exact nature of children's interaction with existing internet/computer mediated and non-computer/internet mediated persuasive designs and systems in both the developed and the developing societies or LDCs.

\section{Conclusion}

CHIPS are already established as effective means of persuading targets, contributing to entrepreneurial and learning successes in the more urbanised societies where accessibility to computers are higher. This knowledge, erroneously, has been the driving force of most persuasive drives engineered by investors, designers, design sponsors and education policy makers in many developing countries. However, the efficacy in effective reach is limited in developing or undeveloped communities where access to computers/persuasive technologies is lower amongst children as revealed in this study. Such developing or underdeveloped communities can be found, as at the time of this study, in many parts of developing countries like Nigeria and Ghana and LDCs like Yemen, Angola, Burundi, Togo, Republic of Vanuatu, Republic of Benin, Comoros, Chad, Mauritania, Republic of Djibouti, Somalia and so on. The less urbanised or computer-exposed a community is, the less effective CHIPS will be in application; hence, the less persuasiveness. This has bred complications such as product/business failure, as well as lack of environmental sustainability and learning limitations which are common features of many developing or underdeveloped societies. However, a blend of both CHIPS and PEHIPS, this study proposes, will yield greater effective reach in such communities as effective persuasive reach is only possible when targets enjoy sufficient accessibility to persuasive systems/technologies, a dearth of which is yet a problem in developing worlds and LDCs.

\section{Acknowledgment}

The author wishes to acknowledge friends, collaborators and mentors at the Federal University of Technology, Akure, Nigeria, including but not limited to: Prof. E. Bankole Oladumiye, Prof. O.F. Kayode, Prof. O.A. Adetunmbi, Prof. I.B. Kashim and Prof. Tolulope Akinbogun as well as others from other institutions such as Prof. (Mrs.) Ebunoluwa Adejuyigbe, Dr. Emmanuel E. Odji and Justice (Mrs.) Eunice A. Alade. Special appreciation is extended to the authorities of schools and parents whose pupils/wards were allowed to participate in this study. The author also appreciates the efforts of research assistants who were untiringly helpful in the course of experimentation, data gathering and analyses conducted.

\section{References}

[1] UN-OHRLLS. (2018). Criteria for Identification and Graduation of LDCs. Retrieved Feb. 28, 2020, from http://unohrlls.org: http://unohrlls.org/about-ldcs/criteria-for-ldcs/

[2] Nwokoye, E. S. (2009). Population Growth and Distribution in Nigeria. In M. O. Ezenwa (Ed.), Social Sciences at a Glance (pp. 69-75). Awka, Anambra, Nigeria: School of General Studies, Nnamdi Azikiwe University.

[3] World Population Review. (2020). Nigeria Population 2020. Retrieved Feb. 17, 2020, from http://worldpopulationreview.com: http://worldpopulationreview.com/countries/nigeria-population/

[4] Ilter, C. (2017). What Economic and Social Factors Affect GDP Per Capita A Study of Four Countries. Journal of Global Strategic Management, 11, 51-62.

[5] Odji, Ebenezer, \& Oladumiye, E. Bankole. (2019). Adopting Improved Need-Analysis, Persuasion and Aesthetics for Alleviating Local Product Design Fiasco. International Journal of Research and Innovation in Social Science, 3(11), 409-418.

[6] Odji, E., Oladumiye, E., \& Kayode, O. (2019). The Impact of Product Dis-credibility on Consumer Behaviour, the Manufacturing Sector and the Designer's Interest. Design In The Nigerian Context; Evolving Indigenous Design Approaches, Concepts, Praxis and Education. 2019 Conference of Visual Communication Design. Akure: Industrial Design Department, Federal University of Technology, Akure, Ondo State, Nigeria.

[7] Odji, E. (2019). Abuse by Design: The Implications and Prospects of Adopting Child-Character Centred Persuasive Designs and Systems. International Journal of Health and Pharmaceutical Research, 5(2 (2019)), 31-48 DOI: 10.5281/zenodo.3660706.

[8] Friestad, M., \& Wright, P. (1994). The Persuasion Knowledge Model: How People Cope with Persuasion Attempts. Journal of Consumer Research, Inc., Vol 21, 1-31.

[9] Torning, K., \& Oinas-Kukkonen, H. (2009). Persuasive System Design: State of the Art and Future Directions. April 26-29, Persuasive'09. Claremont, California, USA: DOI: 10.1145/1541948.1541989.

[10] Ferreira, A., Coventry, L., \& Lenzini, G. (2015). Principles of Persuasion in Social Engineering and Their Use in Phishing. In \&. I. T. Tryfonas (Ed.). Switzerland: Springer International Publishing DOI: 10.1007/978-3-319-20376-8-4.

[11] Kimura, H., \& Nakajima, T. (2011). Designing Persuasive Applications to Motivate Sustainable Behavior in Collectivist Cultures. PsychNology Journal, 9(1), 7-28.

[12] Fogg, B. J. (2003). Persuasive technology: Using computers to change what we think and do. San Francisco, CA, USA: Morgan Kaufmann Publishers Inc. 
[13] Mustaquim, M., \& Nystrom, T. (2015). A System Development Life Cycle for Persuasive Design for Sustainability. In T. MacTavish, \& S. Basapur (Ed.), Persuasive Technology: 10th International Conference, PERSUASIVE 2015, June 3-5 (pp. 217-228). Chicago, IL, USA: Springer International Publishing Lecture Notes in Computer Science http://dx.doi.org/10.1007/978-3-319-20306-5_20.

[14] Lockton, D., Harrison, D., \& Stanton, N. A. (2010). The design with intent method: A design tool for influencing user behaviour Applied Ergonomics, 41(3), 382-392.

[15] Redstrom, J. (2006). Persuasive Design: Fringes and Foundations. In W. I. al. (Ed.), PERSUASIVE 2006 (pp. 112-122). Springer-Verlag Berlin Heidelberg 2006. http://redstrom.se/johan/papers/persuasive_design.pdf

[16] Oinas-Kukkonen, H. (2010). Discipline of Information Systems: A Natural Strategic Alliance for Web Science. Proceedings of the Second International Web Science Conference (WebSci 10) April 26-27 (2010). Raleigh, NC, US: WebSci.

[17] IDF. (2019). Persuasive Design. Retrieved May 2019, 30, from https://www.interaction-design.org/literature/topics/persuasivedesign

[18] Neeraj, A. (2014). Ethics in Advertisement and impact on Women and Children. International Journal of Research in Business Management, 2(6), 19-26.

[19] Fogg, B. J. (2009). A Behavior Model for Persuasive Design. Retrieved August 2017, 25, from bjfogg.com: http://bjfogg.com/fbm_files/page4_1.pdf

[20] Festinger, L. (1975). A theory of cognitive dissonance. Stanford: Stanford University Press.

[21] Davis, F. (1989). Perceived usefulness, perceived ease of use, and user acceptance of information technology. MIS Quarterly, 13(3), 319-339.

[22] Fogg, B. J. (1998). Persuasive Computers: Perspectives and Research Directions. Proceedings of the CHI 98 Conference on Human Factors in Computing Systems (pp. 225-232). Los Angeles: ACM Press/Addison-Wesley Publishing Co.

[23] Simons, H. W., Morreale, J., \& Gronbeck, B. (2001). Persuasion in Society. Thousand Oaks London New Delhi: Sage Publications, Inc.

[24] Oinas-Kukkonen, H., \& Harjumaa, M. (2008). Towards Deeper Understanding of Persuasion in Software and Information System. Proceedings of The First International Conference on Advances in Human-Computer Interaction (ACHI 2008) (pp. 200-205). electronic publication, ISBN 978-0-7695-3086-4.

[25] Oinas-Kukkonen, H., \& Harjumaa, M. (2009). Persuasive Systems Design: Key Issues, Process Model, and System Features. Communications of the Association for Information Systems. 24 Article 28.

[26] Arul, M., \& Vasudevan, V. (2016). Influence of Children on Parent's Buying Behaviour;The Cost And Management. Retrieved July 5, 2017, from http://www.icmab.org.bd/images/stories/journal/2016/3.Influence\%20of\%20Children.pdf

[27] Rule, B., Bisanz, G., \& Kohn, M. (1985). Anatomy of a Persuasion Schema: Targets, Goals, and Strategies. Journal of Personality and Social Psychology, 48 (May), 1127-1140.

[28] Halttu, K., \& Oinas-Kukkonen, H. (2017). Persuading to Reflect: Role of Reflection and Insight in Persuasive Systems Design for Physical Health. Human-Computer Interaction, 32(5-6), 381-412.

[29] Venkatesh, V., Morris, M. G., Davis, G. B., \& Davis, F. D. (2003). User acceptance of information technology: Toward a unified view. MIS Quarterly, 27(3), 425-478.

[30] Venkatesh, V., \& Zhang, X. (2010). Unified theory of acceptance and use of technology: US vs. China. Journal of Global Information Technology Management, 13(1), 5-27.

[31] Moosa Qasim, M., Sadiq Khalaf, H., Raad Abdulkareem, A., \& Md. Yussop, Y. (2018). Design and Development of an Interactive Persuasive Mathematics Game for Primary School Children. International Journal of Engineering \& Technology, 7(4.19), 272-276.

[32] Odji, E., Odewole, O. P., \& Oladumiye, E. B. (2019). Application of Design Theories and Principles for Improving Local Agricultural Products and Packaging Design Aesthetics for Optimized Economic Value. International Journal of Agriculture and Earth Science, 5(2), 1-11.

[33] Lewis, M. A., \& Lockheed, M. E. (2006). Inexcusable Absence: Why 60 Million Girls Still Aren’t in School and What to Do about It. Washington, DC: United Book Press.

[34] Kazeem, A., Jensen, L., \& Stokes, C. (2010). School attendance in Nigeria: understanding the impact and intersection of gender, urban-rural residence and socioeconomic status. Comp Educ Rev., 54(2), 295-319.

[35] Cacioppo, J., \& Petty, R. (1979). Effects of message repetition and position on cognitive response, recall, and persuasion. Journal of Personality and Social Psychology, 37(1), 97-109.

[36] Cacioppo, J., \& Petty, R. (1989). Effects of Message Repetition on Argument Processing, Recall, and Persuasion. Basic and Applied Social Psychology, 10(1), 3-12.

[37] Claypool, H., Mackie, D., Garcia-Marques, T., McIntosh, A., \& Udall, A. (2004). The Effects of Personal Relevance and Repetition on Persuasive Processing. Social Cognition, 22(3, 2004), 310-335.

[38] Weisbucha, M., \& Mackie, D. (2009). False fame, perceptual clarity, or persuasion? Flexible fluency attribution in spokespers on familiarity effects. Journal of Consumer Psychology, 19 (2009), 62-72.

\section{Author's Profile}

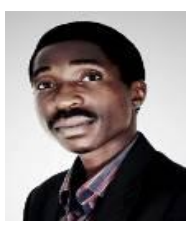

Ebenezer Odji is a researcher with a clear vision who has published research papers in both National and International peer reviewed Journals and Conferences. His current areas of work include Persuasion, Computer Generated Imagery, consumer psychology \& multimedia communication, Local content development, awareness creation, theories \& design applications, sustainability and process optimization. 
How to cite this paper: Odji Ebenezer, " Influencing Children: Limitations of the Computer-Human-Interactive Persuasive Systems in Developing Societies", International Journal of Modern Education and Computer Science(IJMECS), Vol.12, No.5, pp. 1-15, 2020.DOI: $10.5815 /$ ijmecs.2020.05.01 